\title{
Neurological features in SARS-CoV-2-infected patients with smell and taste disorder
}

\author{
Antoniangela Cocco $^{1,4} \cdot$ Paolo Amami $^{1} \cdot$ Antonio Desai $^{2} \cdot$ Antonio Voza $^{2} \cdot$ Fabio Ferreli $^{3} \cdot$ Alberto Albanese $^{1,4}($ ()
}

Received: 19 July 2020 / Revised: 29 July 2020 / Accepted: 30 July 2020 / Published online: 7 August 2020

c) Springer-Verlag GmbH Germany, part of Springer Nature 2020

\section{Dear Sirs,}

By the end of February 2020, the severe acute respiratory syndrome coronavirus 2 (SARS-CoV-2) raided Northern Italy causing an exponential increase of cases [6]. Newonset smell and taste disorders (STD) are common findings in SARS-CoV-2 patients [2], whereas severe neurological symptoms are less commonly observed [8]. The question has been raised whether mild neurological symptoms indicate a neuroinvasive potential of SARS-CoV-2. Ability to invade the central nervous system (CNS) through the olfactory neuroepithelium has been demonstrated for previous strains of coronavirus [3]. Furthermore, nasal epithelial cells display a high expression of the SARS-CoV-2 receptor, angiotensinconverting enzyme 2 [7]. CNS involvement is supported by the observation of MRI abnormalities in the olfactory bulb of some patients with SARS-CoV-2 infection and STD [1, 5]. We studied a cohort of SARS-CoV-2-infected patients with new-onset STD.

The study was approved by the ethics committee of Humanitas Research Hospital. Patients visiting the emergency department of Humanitas, who had SARS-CoV-2 infection confirmed by real-time polymerase chain reaction on nasopharyngeal swabs, were asked to complete an online questionnaire. After providing written online informed consent, the patients answered questions regarding new-onset STD, quality of smell and taste, time of symptom onset

Alberto Albanese

alberto.albanese@unicatt.it

1 Department of Neurology, IRCCS Humanitas Research Hospital, Rozzano, Milano, Italy

2 Department of Emergency Medicine, IRCCS Humanitas Research Hospital, Rozzano, Milano, Italy

3 Department of Otolaryngology, IRCCS Humanitas Research Hospital, Rozzano, Milano, Italy

4 Department of Neuroscience, Catholic University, Milano, Italy and duration, and compiled the Sino-nasal Outcome Test 22 (SNOT-22) [4]. Patients with preceding or concomitant CNS involvement were excluded. Neurological symptoms were collected from electronic hospital notes. Categorical variables were expressed as frequencies (\%), continuous variables as means $( \pm \mathrm{SD})$. For between-group comparisons, the Fisher exact test was used for categorical variables and the $T$ test for continuous variables. The statistical level was set at 0.05 .

One hundred and five eligible patients completed the survey. They compiled questionnaires on average 46.1 ( \pm 19$)$ days after accessing the emergency department. Their main demographic data and clinical features are summarized in Table 1. Their mean age was 56.2 years (range 23-90 years); $40 \%$ were women. Patients with STD were on average 10 years younger than those without. Any altered sense of smell or taste was reported by 78 patients $(74.3 \%$; $95 \%$ CI 64.8-82.3), who had higher total SNOT-22 score and nasal symptoms score compared to patients without STD (Table 1). Overall, $88 \%$ of women had STD compared to $65 \%$ of men. Disease severity, as evidenced by the clinical management at home or in hospital, was unrelated to STD occurrence. Among all patients with STD, 51.3\% recovered smell and $60.3 \%$ recovered taste within 20 days from onset. STD uniformly involved different odors and taste modalities (Table 2).

Patients with new-onset STD had a significantly higher prevalence of mild neurological symptoms compared to patients without STD. Symptoms with higher prevalence in SARS-CoV-2 patients with STD included: headache, balance impairment, dysphonia, dizziness, mild confusion, sensory disturbances, and visual disturbances (Table 1).

In this naturalistic study on SARS-CoV-2-infected patients, we observed that those with STD had a higher prevalence of some neurological symptoms than had patients without STD. This may suggest a direct action of SARSCoV-2 on nasal epithelial cells, and its possible propagation beyond the olfactory bulb. The reported symptoms 
Table 1 Characteristics and symptom prevalence of 105 patients positive for SARSCoV-2 with or without newonset STD

\begin{tabular}{|c|c|c|c|}
\hline Characteristics & STD & No STD & $P$ value \\
\hline Patients ( $n: 105)$ & $78(74.3 \%)$ & $27(25.7 \%)$ & \\
\hline Gender (women/men) & $37 / 41$ & $5 / 22$ & .011 \\
\hline Age (years: mean $\pm S D)$ & $53.7( \pm 11.8)$ & $63.5( \pm 13.5)$ & .001 \\
\hline BMI & $26.8( \pm 4.5)$ & $26.2( \pm 3.6)$ & NS \\
\hline Current smoker (number) & $3(3.8 \%)$ & $1(3.7 \%)$ & NS \\
\hline Management of SARS-CoV-2 infection & & & NS \\
\hline Quarantine at domicile $(n=26)$ & $21(26.9 \%)$ & $5(18.5 \%)$ & \\
\hline Hospitalization in ward only $(n=66)$ & $46(59 \%)$ & $20(74.1 \%)$ & \\
\hline Hospitalization in intensive care unit $(n=13)$ & $11(14.1 \%)$ & $2(7.4 \%)$ & \\
\hline SNOT-22 total score & $40.1( \pm 22.2)$ & $16.8( \pm 14)$ & .000 \\
\hline Nasal symptoms (items $1-4,6-7$ ) & $6.6( \pm 6.9)$ & $2.2( \pm 3.2)$ & .000 \\
\hline Associated neurological features & $71(91 \%)$ & $19(70 \%)$ & .008 \\
\hline Headache & $52(66.7 \%)$ & $8(29.7 \%)$ & $.001^{\mathrm{m}}$ \\
\hline Altered trigeminal sensation & $41(52.6 \%)$ & $2(7.4 \%)$ & $.000^{\mathrm{m}}$ \\
\hline Balance impairment & $39(50 \%)$ & $6(22.2 \%)$ & .012 \\
\hline Dysphonia & $39(50 \%)$ & $7(25.9 \%)$ & $.030^{\mathrm{w}}$ \\
\hline Walking disturbances & $38(48.7 \%)$ & $8(29.6 \%)$ & NS \\
\hline Dizziness & $34(43.6 \%)$ & $5(18.5)$ & .020 \\
\hline Mild confusion & $34(43.6 \%)$ & $5(18.5 \%)$ & .020 \\
\hline Tingling sensations & $28(35.9 \%)$ & $3(11.1 \%)$ & .015 \\
\hline Tremor & $26(33.3 \%)$ & $7(25.9 \%)$ & NS \\
\hline Visual disturbances & $25(32.1)$ & $3(11.1 \%)$ & .034 \\
\hline Hearing impairment & $24(30.8 \%)$ & $5(18.5 \%)$ & NS \\
\hline Reduced sensation & $23(29.5 \%)$ & $2(7.4 \%)$ & .020 \\
\hline Language disturbances & $14(17.9 \%)$ & $1(3.7 \%)$ & NS \\
\hline Fainting/syncope & $13(16.7 \%)$ & $1(3.7 \%)$ & NS \\
\hline Convulsions & $2(2.7 \%)$ & $0(0 \%)$ & NS \\
\hline
\end{tabular}

Between-group comparisons were performed by the Chi-squared test for categorical variables and with the $T$ test for continuous variables. Nested Chi-squared test was used to assess gender influence on significant associations. Significant level $(p<.05)$. Gender influence: ${ }^{\mathrm{m}}$, men with STD had higher prevalence of this feature; ${ }^{\text {w }}$ women with STD had higher prevalence of this feature

$B M I$ body mass index, $N S$ not significant, $S A R S-C o V-2$ severe acute respiratory syndrome coronavirus 2 , SNOT-22 sino-nasal test 22, STD smell and taste dysfunction were mild and not suggestive of anatomically defined CNS lesions, at variance with a direct nervous system lesioning documented in a minority of patients with SARS-CoV-2 infection [8].

In this cohort, STD was unrelated to indices of clinical severity, such as the management at domicile or in hospital. More than half of the patients recovered STD within 3 weeks from onset.

The underlying pathophysiology of neurological manifestations in SARS-CoV-2 remains to be fully determined.
SARS-CoV-2 infection is a systemic disease where mild neurological signs may be overlooked when the clinical picture is dominated by respiratory symptoms or in patients who are isolated at domicile. Their incidence may be higher than reported here. These results must be interpreted with caution, due to unavoidable study limitations. We suggest, however, that consideration be given to performing detailed neurological assessment in patients with SARS-CoV-2 infection and new-onset STD. 
Table 2 Characteristics of altered sense of smell and taste of 78 patients with STD positive for SARS-CoV-2

\begin{tabular}{llc}
\hline Characteristics & No. of patients & Prevalence, \% (95\% CI) \\
\hline $\begin{array}{l}\text { Duration of smell reduction } \\
\quad 20 \text { days }\end{array}$ & 40 & $51.3(39.7-62.8)$ \\
$\geq 20$ days & 25 & $32.1(21.9-43.6)$ \\
$\begin{array}{l}\text { Duration of taste reduction } \\
\leq 20 \text { days }\end{array}$ & \\
$\geq 20$ days & 47 & $60.3(48.5-71.2)$ \\
Altered smell perception & & $30.8(20.8-42.2)$ \\
Coffee & 37 & \\
Perfume & 30 & $47.4(36-59.1)$ \\
Orange & 28 & $38.5(27.7-50.2)$ \\
Vanilla & 27 & $35.9(25.3-47.6)$ \\
Unburned gas & 26 & $34.6(24.2-46.2)$ \\
Vinegar & 24 & $33.3(23.1-44.9)$ \\
Altered taste perception & & $30.8(20.8-42.2)$ \\
Salted & 37 & \\
Umami & 29 & $47.4(36-59.1)$ \\
Sweet & 29 & $37.2(26.5-48.9)$ \\
Bitter & 25 & $32.1(21.9-43.6)$ \\
Acid & 23 & $29.5(19.7-40.9)$ \\
\hline
\end{tabular}

SARS-CoV-2 severe acute respiratory syndrome coronavirus 2

${ }^{\mathrm{a}}$ 95\%CIs were calculated using Clopper-Pearson method

Author contributions A.C.: Design and conceptualized study; analyzed the data. P.A.: Major role in data analysis. A.D.: Patient assessment. A.V.: Patient assessment. F.F.: Design and conceptualized study. A.A.: Design and conceptualized study; analyzed the data.

Funding Supported by intramural research funding.

\section{Compliance with ethical standards}

Conflicts of interest The authors report no competing interest.
Ethical standard The study was approved by the ethics committee of Humanitas Research Hospital. All human studies must state that they have been approved by the appropriate ethics committee and have therefore been performed in accordance with the ethical standards laid down in the 1964 declaration of Helsinki.

\section{References}

1. Aragao M, Leal MC, Cartaxo Filho OQ, Fonseca TM, Valenca MM (2020) Anosmia in COVID-19 associated with injury to the olfactory bulbs evident on MRI. AJNR Am J Neuroradiol

2. Beltran-Corbellini A, Chico-Garcia JL, Martinez-Poles J, Rodriguez-Jorge F, Natera-Villalba E, Gomez-Corral J, Gomez-Lopez A, Monreal E, Parra-Diaz P, Cortes-Cuevas JL, Galan JC, FragolaArnau C, Porta-Etessam J, Masjuan J, Alonso-Canovas A (2020) Acute-onset smell and taste disorders in the context of COVID-19: a pilot multicentre polymerase chain reaction based case-control study. Eur J Neurol

3. Dube M, Le Coupanec A, Wong AHM, Rini JM, Desforges M, Talbot PJ (2018) Axonal transport enables neuron-to-neuron propagation of human coronavirus OC43. J Virol 92

4. Hopkins C, Gillett S, Slack R, Lund VJ, Browne JP (2009) Psychometric validity of the 22 -item sinonasal outcome test. Clin Otolaryngol 34:447-454

5. Politi LS, Salsano E, Grimaldi M (2020) Magnetic resonance imaging alteration of the brain in a patient with coronavirus disease 2019 (COVID-19) and anosmia. JAMA Neurol (in press)

6. Remuzzi A, Remuzzi G (2020) COVID-19 and Italy: what next? Lancet 395:1225-1228

7. Sungnak W, Huang N, Becavin C, Berg M, Network HCALB (2020) SARS-CoV-2 entry genes are most highly expressed in nasal goblet and ciliated cells within human airways. ArXiv (in press)

8. Whittaker A, Anson M, Harky A (2020) Neurological manifestations of COVID-19: a systematic review and current update. Acta Neurol Scand 142:14-22 